\title{
Optimization of Gas Lift Allocation Using Different Models
}

\author{
Tavakoli R ${ }^{1}$, Daryasafar A ${ }^{2 *}$, Mohammad Keyhani ${ }^{3}$ and Milad Behjoomanesh ${ }^{4}$ \\ ${ }^{1}$ School of Chemical and Petroleum Engineering, Shiraz University, Iran \\ ${ }^{2}$ Petroleum Department, Petroleum University of Technology, Iran \\ ${ }^{3}$ Department of Chemical Engineering, Razi University, Iran \\ ${ }^{4}$ Department of Chemical Engineering, Petroleum University of Technology, Iran
}

Submission: March 17, 2017 , 2017; Published: May 25, 2017

*Corresponding author: Daryasafar A Department of Petroleum Engineering, Petroleum University of Technology, Ahwaz, Iran, Tel: +989173770839; Email: amindaryasafar@yahoo.com

\begin{abstract}
Gas lift for oil-gas extraction is a common practice; however, obtaining maximum productivity of a series of set is not a simple tax because high amount of gas lift makes the optimization of few wells at the same time a very hard task. Therefore, data processing approaches based on calculations and computerized modeling has been receiving attention. By modeling well, it could be possible to obtain higher production rate versus less gas consumption. The present paper is a new approach that uses neural functions and genetic algorithm and studies the different aspects of problem solving for gas allocation optimization in five wells. The results showed that artificial neural networks have very good function in modeling gas lift process and creating gas lift performance curve versus classic methods. The differences between the results obtained by artificial neural network in comparison with results that are obtained in classic methods prove this claim.
\end{abstract}

Keywords: Genetic algorithm; Artificial neural network; Gas lift; Allocation optimization

\section{Introduction}

The normal yield of an oil well does not meet the demands of oil industry due to increasing rate of collection. For that reason, using some methods for increasing collection is inevitable. Pump and gas lift is one of the artificial lift approaches; however, it could not be used in all wells with maximum power due to energy consumption problem. In another word, gas lift in a series of well by optimization of the approach is an economicfunctional issue [1].

Studying gas lift is usually performed by using gas lift performance curve. For the first time, Roy \& Cataporan [2] used an analytical method to create gas lift performance curve in a well. This curve is obtained by drawing the data of oil collection values vs. gas lift amount [3].

There are various methods for fitting the gas lift performance curve; including line fitting by using regression and obtaining equation coefficient. The regression method by calculating equation coefficient is a relatively simple method for modeling gas lift performance in oil wells; however, it lacks flexibility and does not pay attention to the nature of data and their logic; therefore, it is opt to be erroneous in using for different wells. In another word, the same model could not be used in all wells. Modeling based on artificial neural network is an approach that could be discussed due to considering the logic of data and withdrawal from placing the data in a cliché frame. The artificial neural network, which is mostly called as neural network in brief, is a mathematical model that acts by being inspired form human neural system [4].

A neural network consist of one or few groups of artificial connected neural cells that process data by using connective and interactive methods. In most cases, neural networks lack compatibility system; that is, changes in their structure take place in learning phase and they improve themselves for modeling. Artificial neural networks have already been used in modeling complicated relations between inputs and outputs/entry-exits and finding existing patterns in data. For gas lift optimization too, these functions have been used for 
lift optimization particularly when it was difficult to obtain mathematical functions [5].

The genetic algorithm (GA) is an explorative search method that copies the natural evolution process. The algorithm model relies on repetitions and using that repetition and accident in genetic algorithm to optimize production and search for maximum power. In another word, GA belongs to a larger class known as evolutionary algorithms that is a solution for optimization problems by using the evolutionary techniques such as inheritance, mutation, selection and etc. [6].

GA has application in bioinformatics, calculation disciplines, engineering, economic, mathematics, physics and other areas. There is a history of using GA in optimizing gas allocation of a single well or a series of few wells. Martinez used this algorithm for the first time for optimization of gas lift collection [7].

A combination of neural network as a model and GA as an optimizer could be used in solving optimization issues. In 1999, Stoisits et al used modeling of a series of well with neural network and optimizing it with GA. Their perspective in using this optimization system was more in the direction of operational parameters such as the pressure of well and lacked the intensive economical aspect [8]. In present paper, five neural models are linked to a GA with suitable inputs for optimizing the five wells at the same time under different operational conditions and the economy of the process has been summed up as well.

\section{Development of Gas Lift Performance Curve by Modeling with Neural Network}

Many models have been suggested for modeling the amount of oil collection against gas lift. For example, second degree model is one of those models that due to unsymmetrical form of gas lift performance curve, it does not create suitable fitting [9]. For this reason, other models have been suggested by the researchers of this field. Alarcon et al. [10] in 2002 and Khishvand [11] tried to determine a suitable model. The Alarcon's model (equation 1) and Khishvand (equation 2) are as follows:

$$
\begin{aligned}
& Q_{\text {oil }}=a_{0}+a_{1} \ell_{\text {gas }}+a_{2} \ell_{\text {gas }}^{2}+a_{3} \ln \left(Q_{\text {gas }}+1\right) \\
& Q_{\text {oil }}=a_{0}+a_{1} \sqrt{Q_{\text {gas }}}+a_{2} Q_{\text {gas }}
\end{aligned}
$$

For modeling with the neural network, a multi-layer feedforward network with 4 hidden layers with 10 tansig neurons in each layer was used. Then, the results of fitting the two models mentioned above (equations 1 and 2) were used to compare the function of the neural network model vs. mentioned classic methods. The results are listed in (Table 1).
Table 1: Correlation coefficient and the sum of squared error for modeling with artificial neurology network, Alarcon model

\begin{tabular}{|c|c|c|c|c|c|}
\hline & Well 5 & Well 4 & Well 3 & Well 2 & Well 1 \\
\hline \multicolumn{6}{|c|}{ Artificial Neural Network } \\
\hline R2 & 99445 & 9998 & 9992 & 9995 & 9998 \\
\hline $\begin{array}{l}\text { Sum of } \\
\text { squared } \\
\text { error }\end{array}$ & 4362.5 & 102.5 & 1800.5 & 3655.9 & 284.5639 \\
\hline \multicolumn{6}{|c|}{ Alarcon Model } \\
\hline R2 & 9745 & 9935 & 9972 & 999 & 9951 \\
\hline $\begin{array}{l}\text { Sum of } \\
\text { squared } \\
\text { error }\end{array}$ & 9722 & 2248 & 3056 & 3040 & 2174 \\
\hline \multicolumn{6}{|c|}{ Khishvand Model } \\
\hline R2 & 9863 & 9799 & 9835 & 9721 & 9829 \\
\hline $\begin{array}{l}\text { Sum of } \\
\text { squared } \\
\text { error }\end{array}$ & 5212 & 6971 & 18090 & 88010 & 7546 \\
\hline
\end{tabular}
and Khishvand model.

The results of Table 1 show that the artificial neural network, Alarcon and Khishvand model has desire fitness. In addition, as Table 1 shows, the highest correlation coefficient and lowest sum of squared errors were obtained by artificial neural networks. Khishvand's model showed weaker results in comparison with Alarcon model on the wells subject of this paper.

It should be mentioned that the above-mentioned result were obtained by using the most usual neural networks without manipulating geometric parameters of the network. Therefore, most probably, by designing network and using more data, those results could be improved considerably. In continuation, the results of drawing gas lift performance curve by using artificial neural networks for five wells are shown (Figure 1).

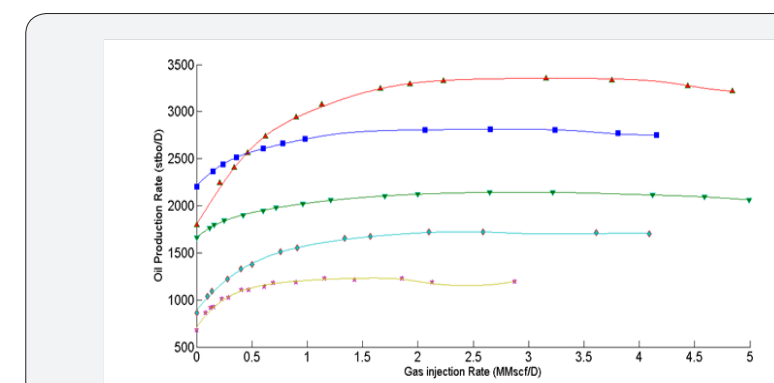

Figure 1: Gas lift performance curve by using artificial networks (well 1 , well 2 , well 3 , well 4 , and well 5).

In Figure 1, the marked dots show the empirical values and the corresponding line of each set of knot shows the neural network model of each well. As it is shown and could be seen in (Table 1) too, suitable agreement of the empirical values and artificial neural network could be seen. On the other hand, by using the model of each one of the wells, quantities such as 
minimum collection of each well, maximum collection of each well and potential for additional collection of each well could be obtained. This information was obtained for all five wells and is listed in (Table 2).

Table 2: Minimum, maximum and potential of oil collection under gas lift process in each well.

\begin{tabular}{|c|c|c|c|c|c|}
\hline & $\begin{array}{c}\text { Well } \\
\mathbf{5}\end{array}$ & $\begin{array}{c}\text { Well } \\
\mathbf{4}\end{array}$ & $\begin{array}{c}\text { Well } \\
\mathbf{3}\end{array}$ & Well 2 & $\begin{array}{c}\text { Well } \\
\mathbf{1}\end{array}$ \\
\hline Maximum (stbo/D) & 1230 & 2145 & 1720 & 3357 & 2813 \\
\hline Minimum (stbo/D) & 680 & 1659 & 865 & 1800 & 2200 \\
\hline Potential (stbo/D) & 550 & 486 & 855 & 1557 & 613 \\
\hline
\end{tabular}

The amount of potential of increasing collection in the process of gas lift has been obtained by differentiating the maximum collection with gas lift and collection in no gas lift conditions. This parameter is independent from gain without gas lift; that is, primary conditions of wells. Due to studying optimized answers, it is interesting to calculate this parameter in order to find out how much the gas allocation between wells in an optimized state would be in relationship with the potential of the wells involved in optimization.

\section{Unrestricted Optimization of Gas Allocation In Wells} and Its Effects on Total Collection

There are different approaches in optimization of a series of well [11]. The approaches could endure different restrictions on the optimization issue. I any way, restrictions such as the range of gas imposing to each well are necessary and inevitable while restrictions such as entry gas originates from economic necessities and studying them is a farther priority than the conditions of gas lift for each well. In this study, we used a trained neural function and linking it to genetic algorithm tool box to optimize the amount of oil production of a series of well and studying the factors. We benefitted from the method of developing the total utilization function and the target function in our issue in most simple situation was maximum total production. This target function could be solved per case without boundaries. For example, the genetic algorithm could be used to obtain maximum total production when less gas lift complex is accessible. In continuation, development and solving little suitable target function is discussed by using common concept in the literature of this discipline and some new suggestions are proposed as well.

\section{Development of the Target Function of Total Production without Economic Boundaries and Restriction}

In this situation, optimization of the sum of wells production will be performed, conditioned by using the amount of gas lift in the scope of model information. The proposed target function and its requisite are described in equations 3 and 4 .

$$
\text { Objective function: } Q_{\text {total ail }}=\sum_{i=1}^{n}\left(Q_{\text {oil }}\right)_{i}=f\left(Q_{\text {gas }}\right)_{1}+f\left(Q_{\text {gas }}\right)_{2}+\cdots+f\left(Q_{\text {gas }}\right)_{n}
$$

$$
0 \leq\left(Q_{\text {gas }}\right)_{i} \leq\left(Q_{\text {availablegas }}\right)_{i}
$$

Development of the target function of total production by economic restriction and studying the effects of economic restriction in productivity

This situation is like previous one with the difference that the sum of entering gas should be less than or equal to a constant amount. In practice, the sum of lift gas should be less than the amount of gas in access. In addition, high costs of the gas make this value to be as low as possible.

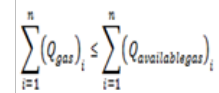

The amount of accessible gas might differ as per operational conditions and therefore, it is interesting to study the effects of gas restriction on the maximum collection conditions. To study this, GA was used. Figure 2 shows the results (55 points) of the calculations. As diagram in (Figure 2) shows, change in total production vs. restriction in total gas lift had an initially strong function and by the increase in amount of gas, the amount of changes and functionality vs. amount of lift restriction reduces accordingly.

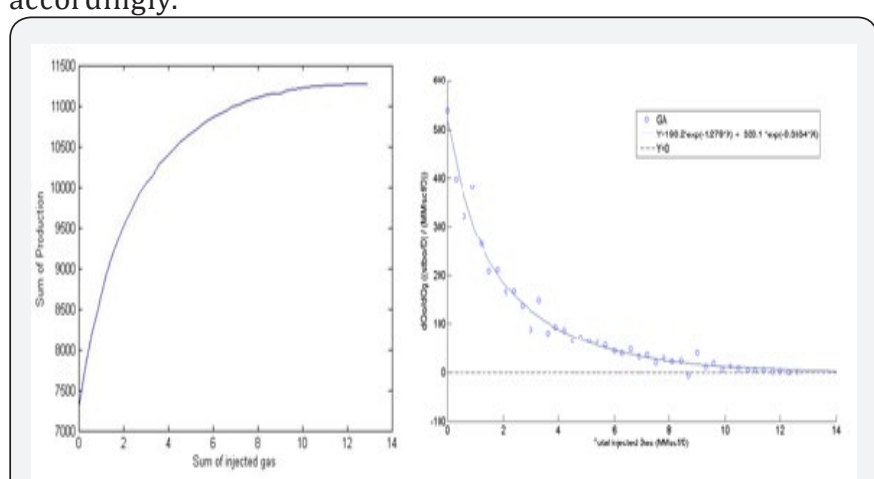

Figure 2: Curve of Oil collection vs. restriction in gas lift and its derivation.

This means that by increasing as to optimized level without restriction (last point in curve), the amount of production increase against consumed gas will be so trivial that would not have economic justification. Hatton et al; too, in studying a field with one hundred wells obtained similar results [12]. In many papers, the limit of 3 million cubic foot standard (MMscf/D) has been defined for total gas arrival in access and observing those conditions in our study could led to $27 \%$ increase in oil production. Due to the importance of using least gas and obtaining highest output, it is important to determine the suitable degree of lift restriction. In following parts, two target functions have been proposed for economic optimization and their results are compared.

\section{Suggestion of Production Target Functions for Achieving Economic Optimizations}

The amount of oil production increase per gas consumption unit could be considered as an important index in lifting 
operations and the largeness of number leads to economic productivity of the oil field. For this reason, this index could be considered as target function to be maximized by using genetic algorithm. For this purpose, two target functions are suggested: The function of sum of net productions of wells and the function of net production of wells and their only difference is in the method of modeling for gas lift production. The function of sum of net production of wells is defined as follows:

$$
\sum_{i=1}^{n} \frac{\left(Q_{\text {oii }}\right)_{i}}{\left(Q_{\text {gas }}\right)_{i}+1}=\frac{f\left(Q_{\text {oii }}\right)_{1}}{\left(Q_{\text {gas }}\right)_{1}+1}+\frac{f\left(Q_{\text {oii }}\right)_{2}}{\left(Q_{\text {gas }}\right)_{2}+1}+\cdots+\frac{f\left(Q_{\text {oii }}\right)_{n}}{\left(Q_{\text {gas }}\right)_{n}+1}
$$

In addition, total net production function is standardized as follows:

$$
\frac{\sum_{i=1}^{n}\left(Q_{\text {oi }}\right)_{i}}{\sum_{i=1}^{n}\left(Q_{\text {gas }}\right)_{i}+1}=\frac{f\left(Q_{\text {oil }}\right)_{1}+f\left(Q_{\text {oil }}\right)_{2}+\cdots+f\left(Q_{\text {oil }}\right)_{n}}{f\left(Q_{\text {gas }}\right)_{1}+f\left(Q_{\text {gas }}\right)_{2}+\cdots+f\left(Q_{\text {gas }}\right)_{n}+1}
$$

Maximum functions (equations 6 and 7) are maximum collection in minimum gas lift. The reason that the denominator of both functions are plus 1 is for keeping the function continuous and preventing infinite answers. (Table 3) lists the results of optimization of those two target functions and optimization without restriction issues:

Table 3: method of gas lift allocation and performance of the presented target functions.

\begin{tabular}{|c|c|c|c|c|c|c|c|c|c|}
\hline $\begin{array}{c}\text { Generator } \\
\text { Target } \\
\text { Function }\end{array}$ & (Stab/D) & (Stab/D) & (Stab/D) & (Stab/D) & (Stab/D) & $\begin{array}{c}\text { Value of } \\
\text { Target } \\
\text { Function }\end{array}$ & $\begin{array}{c}\text { Total } \\
\text { collection } \\
\text { (MMSCF/D) }\end{array}$ & $\begin{array}{c}\text { (Stab/D) } \\
\text { Increase in } \\
\text { production }\end{array}$ \\
\hline Equation 3 & 1.5917 & Feb-83 & Feb-02 & 3.1948 & 2.7637 & 11269.4235 & 1126.4235 & 12.9424 & 355504 \\
\hline Equation 6 & 0.2432 & 0 & 0.2319 & 2306 & 0.0085 & 74250017 & 8276.8193 & 0.7141 & 12.2477 \\
\hline Equation 7 & 0 & 0 & 0.0251 & 0.01448 & 0.001 & 7038.2455 & 7328.2769 & 0.0412 & 0.8894 \\
\hline
\end{tabular}

Economic- performance desirability of the conditions obtained from each target function could be defined with respect to the increase in production divided into sum of lift gas in optimized state. The scale is million cubic foot standard in one power (1/stbd/D). In this case, the boundless optimization desirability of wells will be 2.75 (percent collection improvement/ amount of lift gas), the desirability obtained from optimization function of sum of net production of wells (equation 6) is 17.15 and desirability of optimization of total net production (equation 7) will be 21.59. On the other hand, in many papers, the restricted optimization or maximum accessible gas was concerned while in our study, by including lift restriction of total 3 million cubic foot standard gas per day, the perspective will end to desirability value of 9 which is less than the desirability of suggested target functions.

Therefore, it could be claimed that it is not economical to use all the gas accessible for gas lift project and optimizing the amount of gas lift is a delicate issue; therefore, modeling with neural network and optimizing with GA could be a solution.

Another interesting point is the approach of gas allocation by genetic algorithm. The arrangement of potentials magnitude of wells subject of study is as follows: well 2, well 3, well 1, well 5 and well 4. In optimizing with target function in equations 6 and 7, as Table 3 shows, wells 4, 5 and 1 were not gas lifted and since those functions (equations 6 and 7) show the desirable economic point too, it seems that GA has withdrawn from optimizing the mentioned wells for maximizing economic profit.

It is highly interesting that the mentioned wells were among the poorest wells in the issue and potential in terms of parameter and this shows the importance of potential parameters in gas lift optimization process; because, if only highly potential wells are selected as gas under lift process, most probably, this would lead the load of optimization calculation load and increase in lift output.

\section{Effects of the Number Of Wells Involved In Gas Allocation Optimization}

Resource management in a gas lift project could be performed in various forms. The number of wells in optimization process is one of the issues that are important in this regards. As an example, in a gas lift network with five wells, the subject could be handled in one of the following approaches:

- Optimization of all five wells by using restriction of sum of input gas

- Optimization of a number of wells without restriction and not optimizing other wells

- Optimization of a number of wells with the restriction in total entry gas and not optimizing other well 
The first scenario has been receiving more anticipation; however, scenarios 2 and 3 did not seem much favorable and of course, no suitable comparative study has been performed regarding those approaches. The logic of the first scenarios is its attention to all wells proportion to their potential and economic abilities. In addition, scenario 2 and 3 are elite adoption scenarios and supporting highly potential wells in production with gas stimulation and withdrawal from spending for wells with no potentials. Each one of those scenarios could be studied with respect to the potential of production under gas lift conditions. Here, we plan to study the effect of the number of wells subject of study in an optimization issue without restriction of entry gas. For this purpose, a full fivefactorial trial design matrix was used. The optimization issues with 0 to 5 wells involved in optimization issue were solved by GA in accordance with the developed matrix. In addition the total amount of gas consumption was calculated and the results were listed in following table

Table 4: Effects of the wells involved in optimization issue on the amount of answers

\begin{tabular}{|c|c|c|c|c|c|c|c|c|c|}
\hline No. & $\begin{array}{l}\text { Number of } \\
\text { optimized } \\
\text { wells }\end{array}$ & Well 1 & Well 2 & Well 3 & Well 4 & Well 5 & $\begin{array}{l}\text { Total production } \\
\text { (sbtd/D) }\end{array}$ & $\begin{array}{c}\text { Percent of } \\
\text { production } \\
\text { increase }\end{array}$ & $\begin{array}{c}\text { Amount of gas } \\
\text { consumption } \\
\text { (MMscf/D) }\end{array}$ \\
\hline 1 & 0 & 0 & 0 & 0 & 0 & 0 & 7263.079 & 0 & 0 \\
\hline 2 & 1 & 1 & 0 & 0 & 0 & 0 & 7846.153 & 7.431339 & 1.594548 \\
\hline 3 & 1 & 0 & 1 & 0 & 0 & 0 & 8816.157 & 17.61627 & 3.21979 \\
\hline 4 & 1 & 0 & 0 & 1 & 0 & 0 & 8104.553 & 10.38274 & 2.421589 \\
\hline 5 & 1 & 0 & 0 & 0 & 1 & 0 & 7749.044 & 6.271292 & 2.762996 \\
\hline 6 & 1 & 0 & 0 & 0 & 0 & 1 & 7785.571 & 6.711029 & 1.63062 \\
\hline 7 & 2 & 1 & 1 & 0 & 0 & 0 & 9418.565 & 22.88551 & 5.990623 \\
\hline 8 & 2 & 1 & 0 & 1 & 0 & 0 & 8706.962 & 16.58309 & 5.196213 \\
\hline 9 & 2 & 0 & 1 & 1 & 0 & 0 & 9657.514 & 24.79349 & 5.552459 \\
\hline 10 & 2 & 1 & 0 & 0 & 1 & 0 & 8352.276 & 13.04072 & 5.694287 \\
\hline 11 & 2 & 0 & 1 & 0 & 1 & 0 & 9302.813 & 21.926 & 6.138324 \\
\hline 12 & 2 & 0 & 0 & 1 & 1 & 0 & 8574.236 & 15.291183 & 4.472432 \\
\hline 13 & 2 & 1 & 0 & 0 & 0 & 1 & 8387.494 & 13.40586 & 4.398265 \\
\hline 14 & 2 & 0 & 1 & 0 & 0 & 1 & 9338.707 & 22.22607 & 4.845929 \\
\hline 15 & 2 & 0 & 0 & 1 & 0 & 1 & 8627.172 & 15.81159 & 4.019779 \\
\hline 16 & 2 & 0 & 0 & 0 & 1 & 1 & 8272.492 & 12.20205 & 4.539743 \\
\hline 17 & 3 & 1 & 1 & 1 & 0 & 0 & 10260.04 & 29.21001 & 8.428721 \\
\hline 18 & 3 & 1 & 1 & 0 & 1 & 0 & 9905.358 & 26.67525 & 8.923496 \\
\hline 19 & 3 & 1 & 0 & 1 & 1 & 0 & 9193.756 & 20.99988 & 8.135039 \\
\hline 20 & 3 & 0 & 1 & 1 & 1 & 0 & 10144.33 & 28.40255 & 8.596429 \\
\hline 21 & 3 & 1 & 1 & 0 & 0 & 1 & 9940.418 & 26.93387 & 7.29394 \\
\hline 22 & 3 & 1 & 0 & 1 & 0 & 1 & 9229.537 & 21.30614 & 6.780292 \\
\hline 23 & 3 & 0 & 1 & 1 & 0 & 1 & 10179.79 & 28.65196 & 7.061153 \\
\hline 24 & 3 & 1 & 0 & 0 & 1 & 1 & 8874.901 & 18.16158 & 7.319916 \\
\hline 25 & 3 & 0 & 1 & 0 & 1 & 1 & 9825.569 & 26.07982 & 7.769531 \\
\hline 26 & 3 & 0 & 0 & 1 & 1 & 1 & 9113.963 & 20.30823 & 6.958856 \\
\hline 27 & 4 & 1 & 1 & 1 & 1 & 0 & 10746.83 & 32.41658 & 11.35851 \\
\hline 28 & 4 & 1 & 1 & 1 & 0 & 1 & 10782.66 & 32.64109 & 10.02877 \\
\hline 29 & 4 & 1 & 1 & 0 & 1 & 1 & 10427.98 & 30.35007 & 10.53943 \\
\hline 30 & 4 & 1 & 0 & 1 & 1 & 1 & 9716.341 & 25.24883 & 9.740696 \\
\hline 31 & 4 & 0 & 1 & 1 & 1 & 1 & 10667.04 & 31.911 & 10.1738 \\
\hline 32 & 5 & 1 & 1 & 1 & 1 & 1 & 11269.44 & 35.55067 & 12.96655 \\
\hline
\end{tabular}


The results of (Table 4) show that by increase in number of involved wells, the slope of production increase percentage curve gradually moves down. In another word, for the present five wells, it is predicted that infinite increase in the number of wells subject of optimization will not cause an increase in optimization output. In another word, in our study, increase in the output caused by optimization has a limit and after reaching that limit, the production increase percent will remain fixed. Therefore, observations and calculations made by authors emphasis that the irregular enlargement of the optimization issue of gas lift does not contain economic profit especially for the reason that the facilities and equipment of gas lift are expensive and require using personnel of the utilization party. In addition, enlarging optimization issue prolongs it and makes it difficult to solve. Results of (Table 5) could be used to draw Pareto diagram and determine the general effect of each well on total amount of collection form series of wells. (Figure 3) shows this diagram.

Table 5: Summation of the effect of optimized well on amount of collection.

\begin{tabular}{|c|c|c|c|}
\hline $\begin{array}{c}\text { The Number } \\
\text { of Well } \\
\text { Involved in } \\
\text { Optimization }\end{array}$ & $\begin{array}{c}\text { Average } \\
\text { Total } \\
\text { Production }\end{array}$ & $\begin{array}{c}\text { \% Increase in } \\
\text { Production }\end{array}$ & $\begin{array}{c}\text { Change in \% } \\
\text { of Production } \\
\text { Increase } \\
\text { in Both } \\
\text { Subsequent } \\
\text { Phases }\end{array}$ \\
\hline 0 & 7263.0790 & 0 & - \\
\hline 1 & 8060.295 & 9.891 & 9.891 \\
\hline 2 & 8863.823 & 18.059 & 8.169 \\
\hline 3 & 9666.756 & 24.865 & 6.806 \\
\hline 4 & 10601.710 & 31.491 & 6.626 \\
\hline 5 & 11269.440 & 35.551 & 4.059 \\
\hline
\end{tabular}

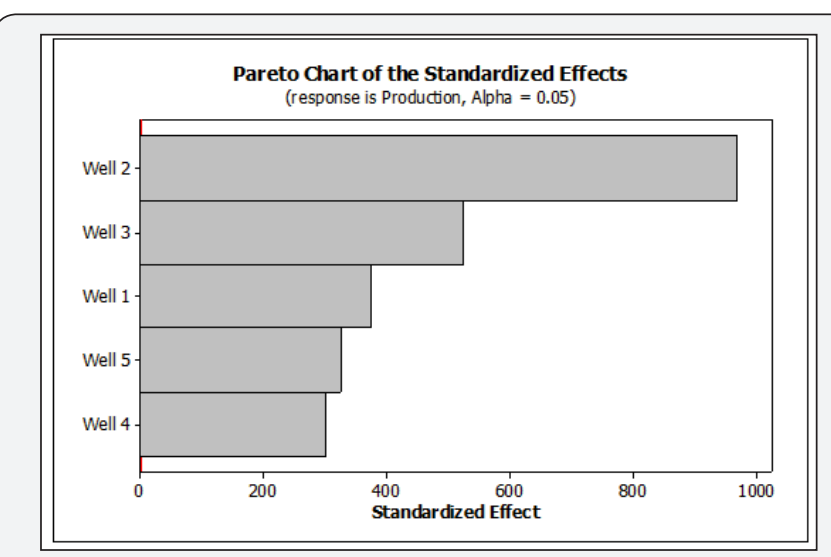

Figure 3: Pareto diagram, standardized effects for the five wells of the issue.

As it could be seen, the effects calculated for wells correspondence with their potentials and since measuring potentials of wells is easier, by considering the results of Table 4 , it is suggested to take the optimization spaces as small as possible and in selecting the wells for optimization, consider the potential factor.

\section{Conclusion}

The most important results obtained in recent research are:

- Artificial neural networks have very good performance for modeling the process of gas lift and making performance curve of gas lift in comparison with classic methods.

- Linking the artificial neural networks (as proximate function) and genetic algorithm could be easily used in optimizing gas lift to oil wells.

- Optimization of the amount of oil production simultaneously, vs., gas consumption in a gas lift without restriction and with restriction is possible. Using new target functions, particularly sum of net products of wells and net total product has more economic value compared to classic views.

- Increase in number of wells involved in optimization issue does not necessarily cause linear increase in economic productivity of total wells. It seems there is a limit and desirable number for wells involved in optimization issue and this issue, along with the cost of equipment and man force generates needs to select the bet wells for as lift.

- The potential parameter could be used as a proposed parameter in selecting wells to be optimized in order to fill the index vacuum of selecting the well.

\section{Acknowledgment}

We take this opportunity to extend our best appreciation to South Oil fields utilization Company for providing us with the information of wells performance curves.

\section{References}

1. Gomez V (1974) Optimization of Continuous Flow Gas Lift Systems. M.S. Thesis. U of Tulsa: Tulsa, Oklahama, USA.

2. Dutta-Roy K, Kattapuram J (1997) new approach to gas lift allocation optimization in Proceedings of $67^{\text {th }}$ Annual Western Regional Meeting, Long Beach, Calif, USA, pp. 685-691.

3. Mayhill TD (1974) Simplified Method for Gas Lift Well Problem Identification and Diagnosis. SPE 5151, SPE $49^{\text {th }}$ Annual Fall Meeting, Houston, Texas, USA, p. 11.

4. Rashid K, Bailey W, Couët B (2012) A Survey of Methods for Gas-Lift Optimization. Modeling Sim. Eng 2012(2012): 16.

5. Mendoza S, de la Cruz RJ, Ruz-Hernandez JA (2009) Neural Networks versus Linear and Sequential programming for Gas Lift Optimization in a two oil wells system, Proceedings of International Joint Conference on Neural Networks, Atlanta, Georgia, USA pp. 3299-3306. 
6. Zerafat MM, Ayatollahi S, Roosta AA (2009) Genetic Algorithms and Ant Colony Approach for Gas-lift Allocation Optimization. J Japan Pet Ins 52(3): 102-107.

7. Martinez ER, Moreno WJ, Moreno JA, Maggiolo R (1994) Application of genetic algorithm on the distribution of gas lift injection. in Proceedings of the $3^{\text {rd }}$ SPE Latin American and Caribbean Petroleum Engineering Conference, Buenos Aires, Argentina, pp. 811-818.

8. Stoisits RF, Crawford KD, MacAllister DJ, McCormack MD, Lawal AS, et al. (1999) Production Optimization at the Kuparuk River Field Utilizing Neural Networks and Genetic Algorithms. Mid-Continent Operations Symposium held in Oklahoma City, Oklahoma, pp. 28-31.
9. Hamedi H, Rashidi F, Khamehchi E (2010) A Novel Approach to the GasLift Allocation Optimization Problem. Pet Sci Tech 29(4): 418-427.

10. Alarcon G, Torres C, Gomez L (2002) Global optimization of gas allocation to a group of wells in artificial lift using nonlinear constrained programming. Energ Resour Tech 124(4): 262-268.

11. Khishvand M, Khamehchi E (2012) Nonlinear Risk Optimization Approach to Gas Lift Allocation Optimization. Ind Eng Chem Res 51(6): 2637-2643.

12. Hatton RN, Potter K (2011) Optimization of Gas-Injected Oil Wells. SAS Global Forum p. 1-4.

\section{Your next submission with Juniper Publishers will reach you the below assets}

- Quality Editorial service

- Swift Peer Review

- Reprints availability

- E-prints Service

- Manuscript Podcast for convenient understanding

- Global attainment for your research

- Manuscript accessibility in different formats

( Pdf, E-pub, Full Text, Audio)

- Unceasing customer service

Track the below URL for one-step submission https://juniperpublishers.com/online-submission.php 